\title{
Reassessment of Steady State Operation in ITER with NBI and EC Heating and Current Drive
}

\author{
A.R. Polevoi ${ }^{1}$, S.Yu. Medvedev ${ }^{2,5}$, G.T.A. Huijsmans ${ }^{3}$, S.H. Kim ${ }^{1}$, A. Loarte ${ }^{1}$, \\ E. Fable ${ }^{4}$, A.A. Ivanov², A.Y. Kuyanov ${ }^{5}$. \\ ${ }^{1}$ ITER Organization, Route de Vinon-sur-Verdon, CS 90 046, 13067 St. Paul Lez Durance \\ Cedex, France, ${ }^{2}$ Keldysh Institute of Applied Mathematics, Miusskaya 4, 125047 Moscow, \\ Russia, ${ }^{3}$ CEA, IRFM, F-13108 Saint-Paul-lez-Durance, France, ${ }^{4}$ Max-Planck Inst. für \\ Plasmaphysik, Boltzmanstraße 2, D-85748 Garching, Germany, ${ }^{5}$ NRC "Kurchatov Institute", \\ Kurchatov sq. 1, 123098 Moscow, Russia
}

Introduction. Demonstration of Steady-State Operation (SSO) with the current fully driven non inductively with the fusion gain $\mathrm{Q}=\mathrm{P}_{\text {fus }} / \mathrm{P}_{\text {aux }} \geq 5$ is one of the goals of the ITER project [1]. The parametric Operational Space (OS) for SSO in ITER has been reassessed by global analysis using inversed transport task approach [2] taking into account the baseline design of the Neutral Beam Injection (NBI) and EC H\&CD systems with $\mathrm{P}_{\mathrm{NBI}}=33 \mathrm{MW}, \mathrm{P}_{\mathrm{EC}}=20 \mathrm{MW}$ and their suggested upgrades, $\mathrm{P}_{\mathrm{NBI}}=49.5 \mathrm{MW}$, and $\mathrm{P}_{\mathrm{EC}}=30 \mathrm{MW}$. The analysis has been carried out for so called Type-II SS scenarios, i.e. the SSO with NBI and EC for heating and current drive H\&CD w/o the LHCD, ICCD and ITBs [3]. The optimal Operational Points (OPs) have been chosen for detailed 1.5-D transport and further MHD stability analysis to demonstrate the $\mathrm{Q}=5 \mathrm{SS}$ goal in ITER, where the bootstrap current, $\mathrm{I}_{\mathrm{bs}}$, an externally driven current, $\mathrm{I}_{\mathrm{cd}}$, fully replace the inductive current, $\mathrm{f}_{\mathrm{NI}}=\left(\mathrm{I}_{\mathrm{bs}}+\mathrm{I}_{\mathrm{cd}}\right) / \mathrm{I}_{\mathrm{p}}=1$. The possibility of the MHD stability control in chosen SSO scenarios by variation of the NBI and ECH\&CD is demonstrated. The feasibility of such scenarios from the point of view of theory, experiments and ITER design limits is discussed.

Global operational SS OS. To derive the SS OS the inversed transport task approach [2] is used. According to this approach the energy confinement required for ITER SSO with $\mathrm{f}_{\mathrm{NI}}=1$, $\mathrm{Q}=5$ is derived as a function of controllable plasma parameters, density, $\mathrm{n}$, and plasma current, $\mathrm{I}_{\mathrm{p}}$, for a chosen set of the H\&CD options. It uses known dependencies of plasma parameters on density and current, $\mathrm{I}_{\mathrm{bs}}=\alpha_{\mathrm{bs}}\left(\mathrm{T}, \mathrm{n}_{0} /<\mathrm{n}>, \mathrm{q}_{\min }\right) \mathrm{n} / \mathrm{I}_{\mathrm{p}}, \mathrm{I}_{\mathrm{CD}, \mathrm{k}}=\mathrm{P}_{\mathrm{k}} \alpha_{\mathrm{k}}\left(\mathrm{T}, \mathrm{Z}_{\mathrm{eff}}\right) / \mathrm{n}, \mathrm{k}=\mathrm{NB}, \mathrm{EC}$, and plasma power balance, $1.5 \mathrm{nT} \mathrm{V}=\mathrm{H} \tau_{\mathrm{E}, \mathrm{y} 2,98}\left(\mathrm{n}, \mathrm{P}_{\mathrm{sol}}, \mathrm{I}_{\mathrm{p}}\right) \mathrm{P}_{\text {sol }}$, [4], with $\mathrm{P}_{\text {fus }} \sim \mathrm{n}^{2} \alpha_{\text {fus }}\left(\mathrm{T}, \mathrm{Z}_{\mathrm{eff}}\right), \mathrm{Q}=$ $\mathrm{P}_{\text {fus }} / \Sigma \mathrm{P}_{\mathrm{k}}, \mathrm{P}_{\text {sol }}=\Sigma \mathrm{P}_{\mathrm{k}}(1+\mathrm{Q})-\mathrm{P}_{\mathrm{rad}}\left(\mathrm{n}, \mathrm{T}, \mathrm{Z}_{\mathrm{eff}}\right)$. Functions $\alpha_{\mathrm{bs}}, \alpha_{\mathrm{k}}, \alpha_{\text {fus }}, \mathrm{P}_{\mathrm{rad}}$ are derived from 1.5D transport simulations on the basis of the Automated System for Transport Analysis (ASTRA) [5], then for the chosen set: $\mathrm{f}_{\mathrm{NI}}=1, \mathrm{Q}=5, \mathrm{n}_{0} /<\mathrm{n}>=1.3, \mathrm{q}_{\min } \sim 1, \mathrm{Z}_{\mathrm{eff}} \sim 2$, the inversed transport task is solved numerically for each set of $\mathrm{H} \& \mathrm{CD}$ options, $\mathrm{P}_{\mathrm{k}}$. The derived functions for confinement, 
$\mathrm{H}=\mathrm{H}_{\mathrm{fQP}}\left(\mathrm{I}_{\mathrm{p}}, \mathrm{f}_{\mathrm{NI}}, \mathrm{Q}, \Sigma \mathrm{P}_{\mathrm{k}}\right)$, and density, $\mathrm{n}=\mathrm{n}_{\mathrm{fQP}}\left(\mathrm{I}_{\mathrm{p}}, \mathrm{f}_{\mathrm{NI}}, \mathrm{Q}, \Sigma \mathrm{P}_{\mathrm{k}}\right)$, are displayed in the figure 1 together with the normalized beta, $\beta_{\mathrm{N}}=\beta \mathrm{aB} / \mathrm{I}_{\mathrm{p}}[\%, \mathrm{mT} / \mathrm{MA}], \mathrm{P}_{\text {sol }}$, and maximum load on the divertor

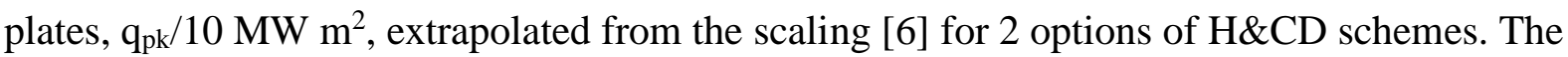
operational points $\mathrm{A} 1\left(\mathrm{I}_{\mathrm{p}}=9 \mathrm{MA}\right)$ for the baseline scheme $\mathrm{P}_{\mathrm{NBI}}=33 \mathrm{MW}, \mathrm{P}_{\mathrm{EC}}=20 \mathrm{MW}$, and $\mathrm{A} 2\left(\mathrm{I}_{\mathrm{p}}=10 \mathrm{MA}\right)$ for an upgrade scheme, $\mathrm{P}_{\mathrm{NBI}}=49.5 \mathrm{MW}, \mathrm{P}_{\mathrm{EC}}=30 \mathrm{MW}$, are chosen for detailed 1.5D transport analyses and further MHD stability analysis. Note that for $\mathrm{I}_{\mathrm{p}}>11 \mathrm{MA}, \mathrm{q}_{\min }<1$ and sawteeth become unstable at least in the frame of ideal MHD.
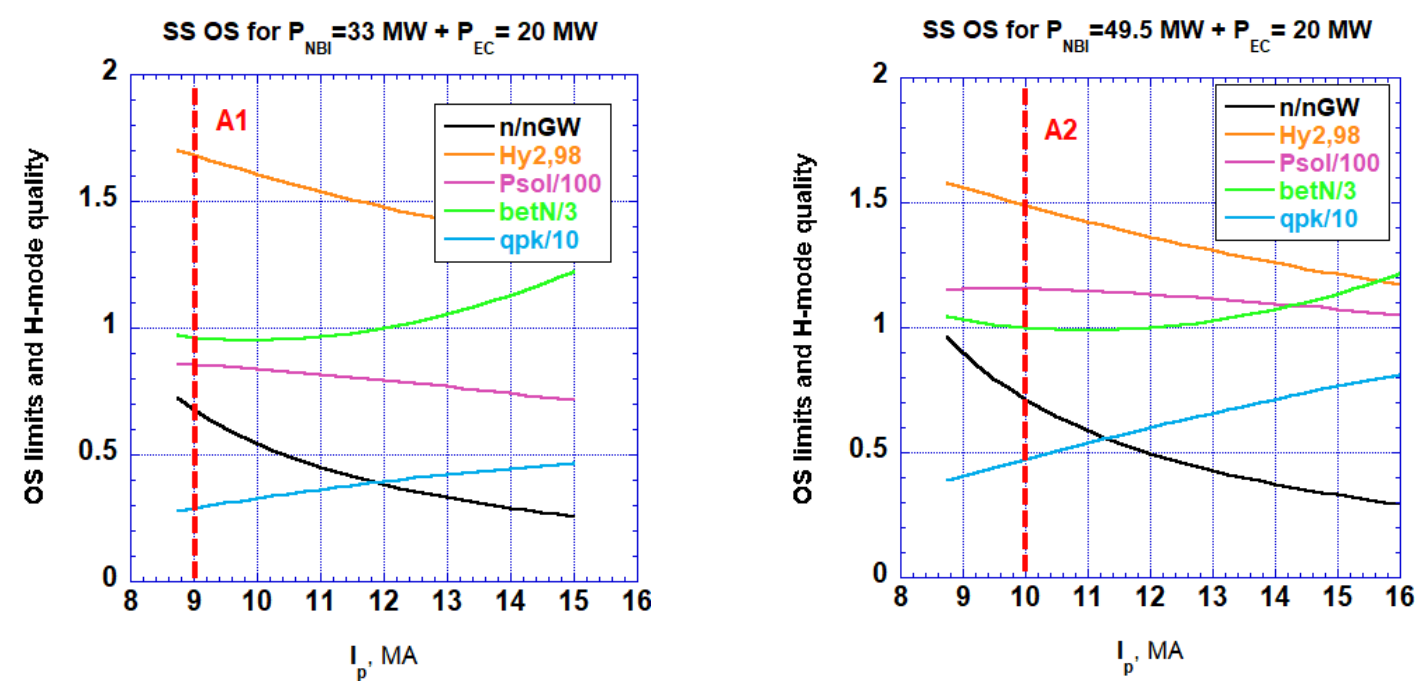

Figure 1. Steady-state operational space for $\mathrm{P}_{\mathrm{aux}}=53 \mathrm{MW}$ (left) and $\mathrm{P}_{\mathrm{aux}}=70 \mathrm{MW}$ (right)

1.5D Transport simulations. The 1.5D transport simulations are carried out by ASTRA for the electron and helium densities, $\mathrm{n}_{\mathrm{e}}, \mathrm{n}_{\mathrm{He}}$, ion and electron temperatures, $\mathrm{T}_{\mathrm{i}}, \mathrm{T}_{\mathrm{e}}$, and current density, $\mathrm{j}$, with the SOLPS boundary conditions with controllable divertor detachment [6] and EPED1+SOLPS pedestal [7], with the particle diffusivity and pinch velocity, $D=\left(\chi_{i}+\chi_{e}\right) / 10$, $\mathrm{V}=0.3 \mathrm{Dx} / \mathrm{a}$. The heat diffusivities, $\chi_{\mathrm{i}}=\chi_{\mathrm{e}}$, are fitted to provide the SSO, $\mathrm{f}_{\mathrm{NI}}=1$. The fuelling is fitted to provide the $\mathrm{Q}=5 \mathrm{SS}$ OPs densities $\mathrm{A} 1, \mathrm{~A} 2, \mathrm{n} \sim 0.7 \mathrm{n}_{\mathrm{GW}}$. The impurities are prescribed as $\mathrm{n}_{\mathrm{Be}} / \mathrm{n}_{\mathrm{e}}=2 \%, \mathrm{n}_{\mathrm{Ne}} / \mathrm{n}_{\mathrm{e}}(\mathrm{a}) \sim 0.6-0.7\left(\mathrm{Z}_{\mathrm{eff}} \sim 1.7\right)$. Following the ECR H\&CD design we assume the sharing of the power between the Equatorial and Upper Launcher (EL,UL) as, $\mathrm{P}_{\mathrm{EL}} / \mathrm{P}_{\mathrm{UL}}=$ 2, with the innermost UL fixed aiming, $\mathrm{x}_{\mathrm{ULEC}}=0.43$, and with the EL ECRH\&CD location steered in the range $\mathrm{x}_{\mathrm{ULEC}}=0.35-0.5$ for plasma safety factor and pressure profile control, $\mathrm{q}(\mathrm{x})$, $\mathrm{p}(\mathrm{x})$. For the NBI H\&CD we assume for the baseline one NBI of $16.5 \mathrm{MW}$ with the innermost aiming $Z_{\text {in }}=0.156 \mathrm{~m}$, and one NBI of $16.5 \mathrm{MW}$ with the outermost aiming $Z_{\text {out }}=-0.417 \mathrm{~m}$. For the upgrade option we assumed the third NBI of $16.5 \mathrm{MW}$ with varying aiming $\mathrm{Z}_{\text {out }}<\mathrm{Z}<\mathrm{Z}_{\text {in }}$. Control of MHD stability of SS operation. The MHD stability analysis is carried out using consistent 1D profiles and 2D equilibria simulated by ASTRA for chosen operational points. 
The results of MHD analysis for the reference H\&CD geometry with ECH\&CD at $\mathrm{x}=0.43$ for the cases A1, A2, carried out with the code KINX [8], are shown in the figure 2 . The $\beta_{N}$ is within the MHD stability limits meanwhile the modes with the toroidal numbers $n=2$ (A1) and $\mathrm{n}=3,4(\mathrm{~A} 2)$ are just marginally stable.
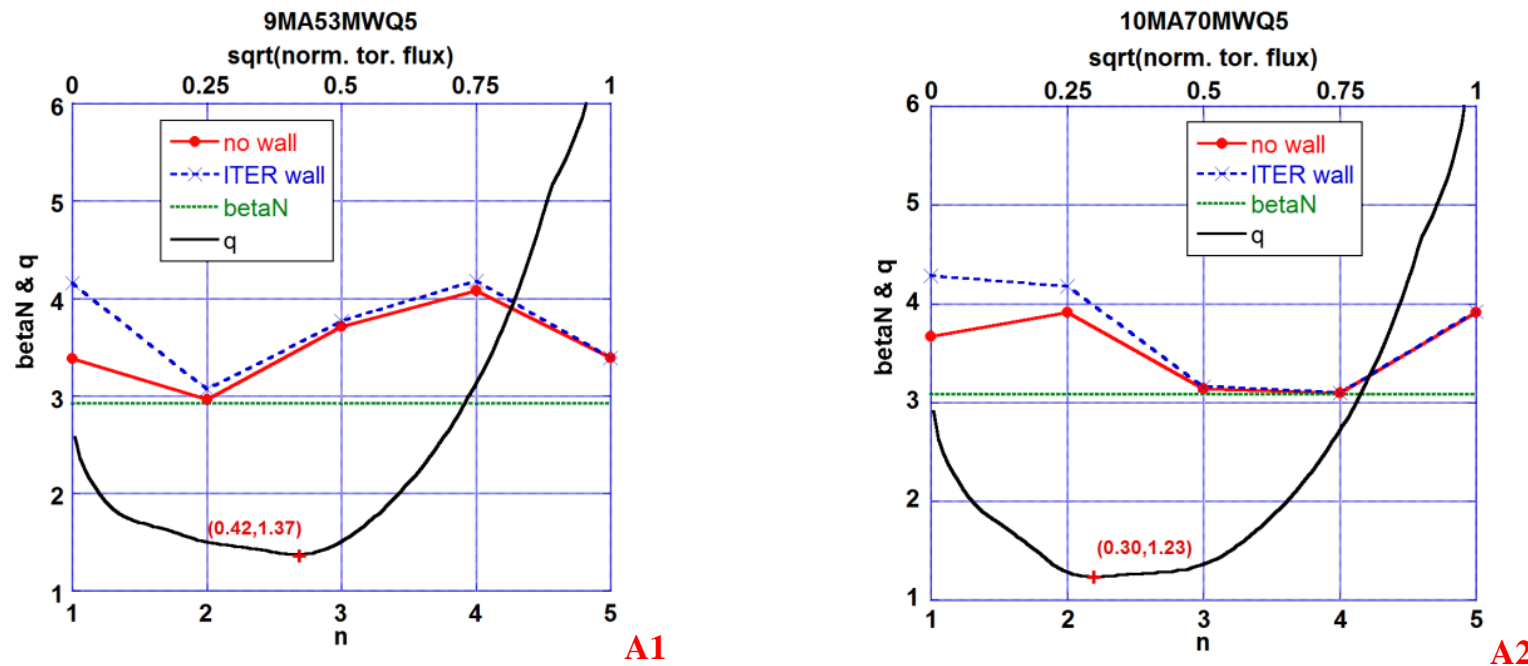

Figure 2. MHD stability analysis for OP (left) at OP A1 ( $\mathrm{x}_{\mathrm{EC}}=0.43,16.5 \mathrm{MW} \mathrm{NBI}$ at $\mathrm{Z}_{1}=0.156 \mathrm{~m}, 16.5 \mathrm{MW}$ at $\left.\mathrm{Z}_{2}=-0.417 \mathrm{~m}\right)$ and $\mathrm{OP}$ at $\mathrm{A} 2$ (right) $\mathrm{A} 2\left(\mathrm{x}_{\mathrm{EC}}=0.43,16.5 \mathrm{MW} \mathrm{NBI}\right.$ at $\mathrm{Z}_{1}=0.156 \mathrm{~m}, 33 \mathrm{MW}$ at $\left.\mathrm{Z}_{2}=\mathrm{Z}_{3}=-0.417 \mathrm{~m}\right)$

Improvement of stability by $\mathbf{E C}$ and NBI variation. For the case A2 variation of the deposition of the ECRH\&CD by steering of the equatorial launcher (figure 3) for the reference NBI geometry helps to provide the operation comfortably far from the MHD stability limits.
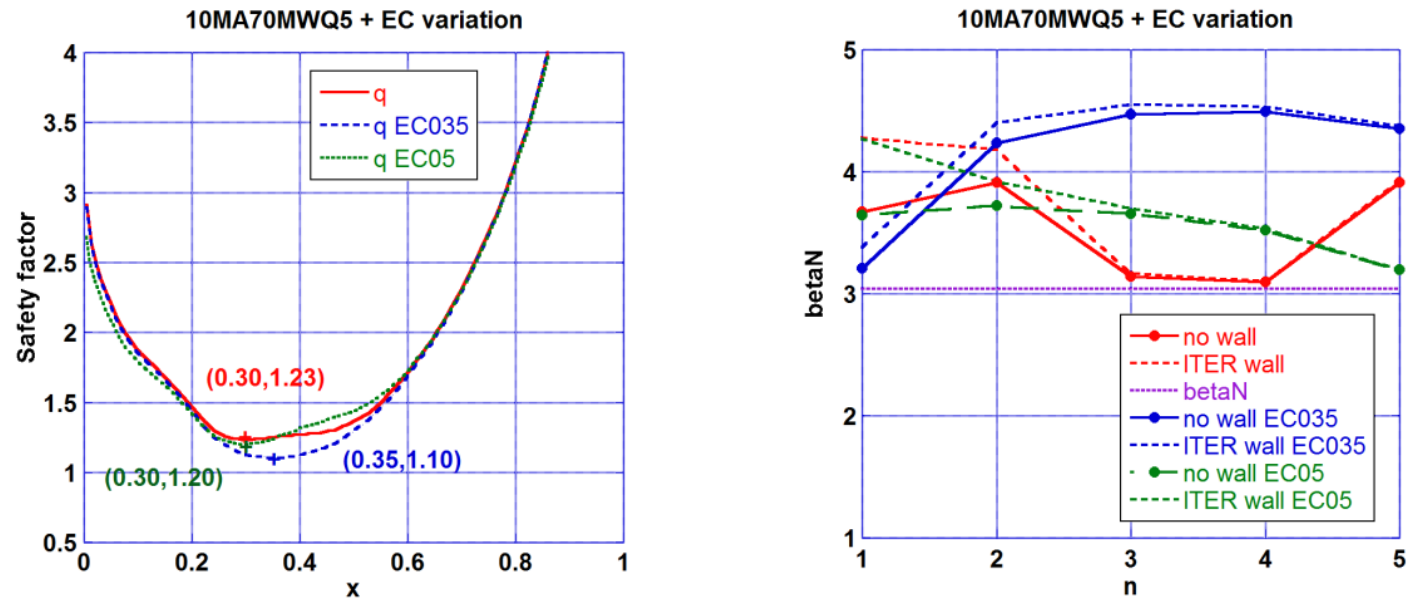

Figure 3. Stability control by ECRH\&CD variation for the operational point A2.

Variation of the $3^{\text {rd }} \mathrm{NBI}$ modifies the ECRH\&CD optimization (figure 4). In particular for $Z_{3}$ $=0.056 \mathrm{~m}$ the only stable $\mathrm{OP}$ corresponds to $\mathrm{x}_{\mathrm{ECEL}}=0.5$. For $\mathrm{Z}_{3}=\mathrm{Z}_{\text {in }}=0.156 \mathrm{~m}$ the safety factor drops below 1 for all variations of the ECCD making such configuration unstable to sawteeth. The $n=1$ limiting $\beta_{\mathrm{N}}$ drop for the EC035 case is caused by infernal mode destabilization due to wide low shear region near $\mathrm{q}_{\min }=1.028$.

Discussion and conclusions. The ITER goal Q=5 SS Operation in ITER looks possible w/o 
ITBs, LHCD and ICCD, with 33-49.5 MW of NBI + 20-30 MW of ECRH\&CD in the range $\mathrm{I}_{\mathrm{p}}$ $=9-10$ MA with high $1_{\mathrm{i} 3} \sim 0.8-0.95, \beta_{\mathrm{N}} \sim 3, \mathrm{n} / \mathrm{n}_{\mathrm{GW}} \sim 0.7-0.8$, provided a high confinement can be reached: $\mathrm{H}_{\mathrm{y} 2.98}$ 1.4-1.6. Control of profiles of plasma pressure and current density by ECH\&CD and NBI variations foreseen by ITER design enables keeping operation within the MHD stability limits. The temperature and density scale lengths, $\mathrm{R} / \mathrm{L}_{\mathrm{T}} \sim 5-6, \mathrm{R} / \mathrm{L}_{\mathrm{n}} \sim 1.3$,
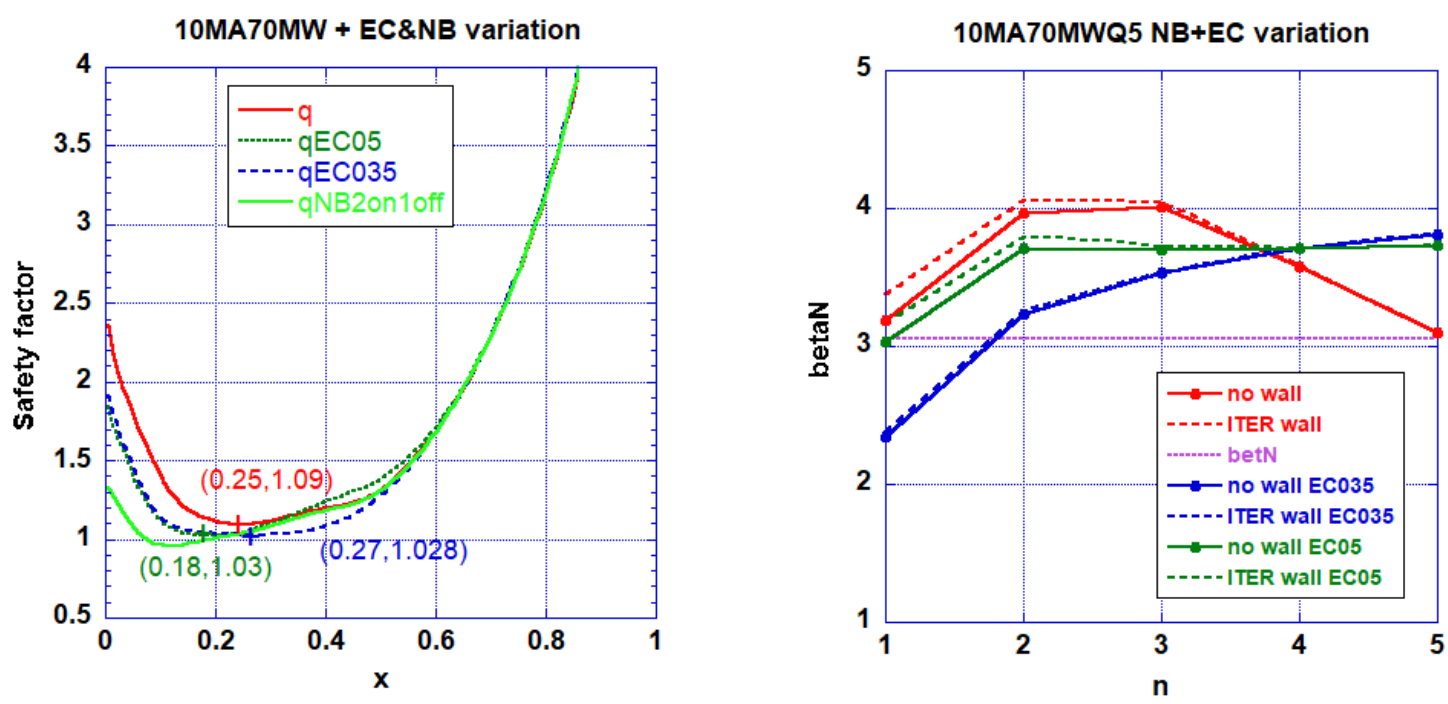

Figure 4. Stability control by NBI and ECRH\&CD variation for the operational point A2

sufficient to achieve the confinement required for SSO in ITER are in good agreement with first principle transport and DIII-D experiments [9]. The SSO in ITER is within the technical design limitations for CS/PF magnets' system [10] and extrapolated divertor power loads [6]. The reduced requirements, $\mathrm{Q}=4, \mathrm{f}_{\mathrm{NI}}=0.9$, make an operation comfortably far from the MHD stability limits. To strengthen the basis for this scenario in ITER dedicated experiments are required in lower $\mathrm{SN}$ configuration with high density $\mathrm{n}>0.5 \mathrm{n}_{\mathrm{GW}}$, and $\mathrm{q}_{0} \sim 2-3$. The SOLPS simulations are required for high power/low current $(\mathrm{q}>4)$ operation with tungsten divertor to refine the core-edge integration requirements of this scenario.

Disclaimer: The views and opinions expressed herein do not necessarily reflect those of the ITER Organization

[1] Y. Shimomura, et al., Plasma Phys. Contr. Fusion, 43 (2001) A385

[2] A.R. Polevoi, et al, “Assessment of operational space for long-pulse scenarios in ITER”, P2.187, EPS2010

[3] A.R. Polevoi, et al, Nucl. Fusion 45 (2005) 1451; C. Gormezano, et al, Nucl. Fusion 47 (2007) S285

[4] ITER Physics Basis 1999 Nucl. Fusion 392208

[5] G.V. Pereverzev and P.N. Yushmanov, 2002 ASTRA, IPP-Report IPP 5/98

[6] H.D. Pacher, et al, Journal of Nuclear Materials 363-365 (2007) 400-406

[7] A.R. Polevoi et.al., Nucl. Fusion 57 (2017) 02201

[8] L. Degtyarev, et al, Computer Physics Communications, Volume 103, Issue 1, June 1997, Pages 10-27

[9] F. Turco, et al, EX3-3, FEC2018

[10] S.H. Kim, “Assessment of access to ITER steady-state operation without LHCD”, to be submitted to NF 